\title{
Fostering Identity and Disposition Development in Jewish Education: A View from the Learning Sciences
}

Janet L. Kolodner

\begin{abstract}
Tn this second chapter drawn from the area of science education, Janet Kolodner draws insight from her Learning by Design approach, through which learners not only grapple with subject matter but also come to "see themselves as scientists and engineers." Kolodner, like Dorph and Schunn in the preceding chapter, sees an analogy to Jewish education's goals in the area of identity. Knowledge, ability, and identity are inextricably intertwined. The author draws on ideas about learning in communities of practice to emphasize the need to create opportunities for Jewish learners to enact valued, authentic Jewish activities in social contexts. She concludes by using the case of her Kitchen Science Investigator program as a springboard for recommendations for Jewish education.
\end{abstract}

During the late 1990s and early 2000s, I was involved in designing a new approach to science education for middle school, a project-based approach that used engineering design projects as a context for learning science content, the practices of scientists and engineers, and communication, collaboration, and project practices. The approach, called Learning by Design ${ }^{1}$ (LBD) has learners playing the roles of scientists and engineers as they work on achieving design challenges. Acting as civil engineers, they design ways of managing water flow and erosion around a basketball court. Acting as mechanical

1 Janet L. Kolodner et al., "Problem-Based Learning Meets Case-Based Reasoning in the Middle-School Science Classroom: Putting Learning by Design into Practice," Journal of the Learning Sciences 12, no. 4 (2003): 495-547; "Learning by Design," Georgia Institute of Technology, http://www.cc.gatech.edu/projects/lbd/home.html. 
engineers and physicists, they design vehicles and their propulsion systems that can navigate different terrains. Acting as geologists, they give advice to civil engineers about where to take core samples to determine the rock formations across Georgia so that a train tunnel can be planned at the appropriate depths across the state. They plan investigations, carry them out, analyze data, read appropriate resources, make sense of what they are experiencing, explain results, and so on-sometimes in small groups, other times as presenters to the whole class, and other times as advisors to other small groups. They live the lives of scientists and engineers for forty-five minutes a day over a fifteen or twenty-week period.

As we had hoped, students learned science content and scientific practices very well. ${ }^{2}$ In addition, something very interesting happened that we had not expected. Many students came to see themselves as scientists or engineers - people who investigate to answer questions, take the design of investigations seriously so that they can trust results, attempt to mechanistically explain phenomena, solve problems and make design decisions based on the needs of the context, and so forth. Not only did they report that to us, but they exhibited an array of behaviors that supported their claims. They presented to the class, sought out advice from their peers, and advised each other in "professional" tones and using rigorous scientific language. They did their best to be respectful to each other when countering each other's claims. They interacted with others in ways that showed they assumed others could learn and wanted to learn from them. They asked each other questions, reveled in each other's successes, and did their best to give each other good advice, even when there was a competition involved. When presented with (made up) shoddy or confused work by those who should have known better (e.g., high schoolers or professionals), they expressed disbelief about how confused and unprofessional that work was and what those others were not aware of.

These results were stunning. Without knowing how to foster identity development, we had somehow designed learning experiences that made students into comfortable scientific and technological thinkers and that caused many of them to adopt behaviors and dispositions, and perhaps even the identity of scientists and engineers, in the classroom. Learning by Design was designed to foster science learning; it seemed to result as well in scientist and

2 Kolodner et al., "Problem-Based Learning," 495-547; Janet L. Kolodner et al., "Promoting Transfer Through Case-Based Reasoning: Rituals and Practices in Learning by Design Classrooms," Cognitive Science Quarterly 3, no. 2 (2003): 183-232. 
engineer identities. We sought to find out what was responsible for this identity development.

In this chapter, I present the literature I've used to understand how to foster such identity development-both the theory framing what I've learned and some of the practicalities of implementation I've considered and identified. My hope is that what I've learned will be useful in development of Jewish education approaches that foster Jewish identity development. Such approaches will successfully help youngsters develop and use a Jewish lens as they navigate the world and become people who make "doing and being Jewish" a core part of who they are. I do not, however, make assumptions about what particular core Jewish identity we seek to nurture. We recognize many different flavors of Jewish identity among those we identify as doing and/or being Jewish: some ardently follow halakhah, some feel strong affiliation with Jews as a people, some feel strong affiliation with Israel as a homeland, some focus on social justice as the core Jewish identity, and so forth. The suggestions I make are independent of what particular Jewish identity educators are aiming to foster; they will work just as well for whatever Jewish identity one is aiming to promote.

\section{Background}

By identity, I refer to the feeling of being a certain kind of person and taking on the attitudes, beliefs, and practices of that kind of person. It could be as simple as "I'm a person who likes (or hates) to cook" or as sophisticated as "I'm a Conservative Jew" or "I'm a particular kind of researcher who believes in certain types of methods and the need for certain types of evidence." While people try out and take on temporary or situational identities as they engage in different activities and different groups, they define themselves (consciously or unconsciously) through a "core identity" that embodies the essentials of what they believe in and influences the attitudes and beliefs they bring to new situations and the key practices and behaviors they engage in. In Learning by Design, students developed situational identities as scientists and engineers as they worked toward achieving scientific and engineering challenges in the classroom. They took on scientific and engineering practices, attitudes, and beliefs even when not specifically required, leading us to infer that they were working toward integrating aspects of those situational identities into their core identities. Our goals in Jewish education are not just that our students will know and be able to do things that are identified as "Jewish." Our aim is that our students will make "being and doing Jewish" a part of their core — that they 
will, over time, integrate beliefs, attitudes, and practices consistent with being some type of Jew into their core identities. Our hope is that this would result in behaving in ways consistent with those beliefs and attitudes even when not in the presence of teachers and parents who expect it in their presence, just as Learning by Design students were doing with the beliefs, attitudes, and practices of scientist and engineers.

By disposition, I mean the inclination to take initiative to carry out the practices and play the roles of those one feels like, as the Learning by Design students did when looking at the work of others and critiquing it. Jewish dispositions might mean being observant in some ways, celebrating at certain times and in certain ways, standing up for Israel, and/or considering Jewish values and ways of thinking when making decisions.

Research shows that fostering such identity and disposition development is more complex than many educators have been led to believe. There are several common (mis)understandings of identity that are implicitly (and sometimes explicitly) brought to bear in educating. Some think that if we aim for learners to learn a lot and become competent at what we are hoping for, identity will develop as a natural consequence. The idea here is that identity develops from understanding and capability. Once learners know things and know how to do things, they will have the disposition (take the initiative) to do other related and similar things. Others believe that if we bombard learners with positive emotional experiences and help them understand and feel just how important all of the things they are experiencing are, then they will develop identity and disposition as a result. The idea here is that identity will develop from experiences that help someone know how he/she belongs, and then learners will have the disposition to do things that those with that identity do. The first of these is an assumption that long-term identity follows from learning; the second, that many moments of identifying are enough for fostering and sustaining core long-lasting identity.

The relationships between identity, learning, experience, and emotion, however, are far more complex and nuanced than what either of these conceptions assumes. The literature suggests that for long-term and core identity development, it is essential to begin with activities learners can easily identify with, to use those to help learners develop curiosity and identify personal goals for learning, and to help them develop understanding and capabilities along with new personal goals. ${ }^{3}$ The literature tells us that learning and

3 Angela Calabrese Barton and Edna Tan, “We Be Burnin'! Agency, Identity, and Science Learning,” Journal of the Learning Sciences 19, no. 2 (2010): 187-229; Tamara L. Clegg and 
identity are intricately intertwined, such that learning, goals, and identity all drive each other's development, ${ }^{4}$ and further, that without fostering identification with learning goals and activities, neither targeted identity nor deep learning will systematically develop. Identification with what one is about to learn is required for learning; learning produces new goals; new goals lead to updated identity, and vice versa; they all influence each other. Identity gives rise to goals, which give rise to learning goals and learning activities as a way to achieve goals, which gives rise to identity refinement. Goals are a mediator for learning and identity; they influence each other through generation and attempted achievement of goals.

From this theoretical perspective, development of understanding, capabilities, and identity need to be addressed simultaneously in designing curriculum and learning environments. The big challenges, this theory suggests, are to figure out the kinds of experiences and facilitation of learning from those experiences that will promote both positive feelings and curiosity, and to follow up immediately with new experiences that address the new curiosity and deepen understanding. Further, educators are challenged to help learners identify and appreciate what they are learning, see its usefulness to them, and identity what they still need to learn. Finally, they must continue to strengthen learning (understanding and capabilities), goals (curiosity and want to learn more), and identity (who I am that makes all this important to me) in conjunction with each other.

Theories abound about how identity develops and how to foster positive identity development. A set that seems particularly relevant to educating toward identity development focuses on identity showing itself and developing through group affinity and participation. Erik Erikson ${ }^{5}$ posited that one's identity is an interaction between how one perceives oneself and how one

Janet L. Kolodner, "Bricoleurs and Planners Engaging in Scientific Reasoning: A Tale of Two Groupsin OneLearningCommunity," Research andPracticein TechnologyEnhancedLearning2, no. 3 (2007): 239-65; Na'ilah Suad Nasir, "Identity, Goals, and Learning: Mathematics in Cultural Practice," Mathematical Thinking and Learning 4, no. 2-3 (2002): 213-47; Na'ilah Suad Nasir and Victoria Hand, "From the Court to the Classroom: Opportunities for Engagement, Learning, and Identity in Basketball and Classroom Mathematics," Journal of the Learning Sciences 17, no. 2 (2008): 143-79; Joseph L. Polman and Diane Miller, "Changing Stories: Trajectories of Identification Among African American Youth in a Science Outreach Apprenticeship," American Education Research Journal 47, no. 4 (2010): 879-918.

4 See, for example, Nasir, "Identity, Goals, and Learning," 213-47.

5 Erik H. Erikson, Dimensions of a New Identity (New York: W. W. Norton \& Company, 1979). 
is seen and treated by others; that such self-concept changes over time and interactions with others; and that its development comes from simultaneous activity, observation, and reflection.

Etienne Wenger ${ }^{6}$ took the idea of group membership and its roles in fostering identity several steps further, seeing identity in terms of membership in Communities of Practice ( $\mathrm{CoPs}$ ) - a group of people who share beliefs and ways of doing. According to this approach, learning involves acclimating to the norms of the community and becoming more able to carry out its practices. Such acclimation (or enculturation) best begins, Wenger claims, through Legitimate Peripheral Participation (LPP $)^{7}$ — when one has a chance to see the whole picture of the community and what its participants do, and one engages at one's level of capability and, with the help of others, develops competence that allows one to gradually become more central to the community. Wenger claims that one develops identity through such participation in each community one is part of, and identity development itself happens through engagement, imagination, and alignment. In each Community of Practice one belongs to, one engages in the community's activities with others; one notices what others are doing and thinking and imagines one's future self in those situations (or rejects them), and one works toward aligning oneself with one's imagination. Others in the community (and outside) play roles in helping one shape one's imagination and pathways to alignment. I like to add awareness to engagement in Wenger's cycle. The cycle, then, is that awareness and engagement drive imagination, which drives alignment, which results in awareness of new things and engagement in new activities, and so forth.

James Paul Gee ${ }^{8}$ adds more specificity to what it means to identify with a group and to the relationship between the kind of person one is within a particular group and one's core identity. Core identity is the set of values, beliefs, attitudes, and practices one engages in/with from group to group as one participates. Our core identity, Gee says, comes from our pathways through the many communities we participate in - the views, norms, and ways of being we take from each of those communities and assimilate into our ways of engaging in other communities. Developing core identity, Gee asserts, involves

6 Etienne Wenger, Communities of Practice: Learning, Meaning, and Identity (Cambridge, UK: Cambridge University Press, 1998).

7 Jean Lave and Etienne Wenger, Situated Learning: Legitimate Peripheral Participation (Cambridge, UK: Cambridge University Press, 1991).

8 James Paul Gee, "Identity as an Analytic Lens for Research in Education," Review of Research in Education 25 (2000-2001): 99-125. 
synthesizing across identity developed in different contexts and communities, choosing those aspects that one values, and bringing them to other contexts and communities one engages with.

A big part of identity development, as stated earlier, is learning how to do the things that are done in a community and learning whatever content one needs to know to do those things. Na'ilah Suad Nasir, ${ }^{9}$ recall, articulates relationships between identity, goals, and learning. Other researchers, as well, tell us that identity development rests on development of competence, the motivation to participate, opportunities for showing one's skills and understanding, and recognition by oneself and others of one's capabilities. ${ }^{10}$

Disposition, it follows, develops from practice in using what one is learning across a variety of situations and requires valuing the practices one is learning, developing capabilities of using the content and skills one is learning across a variety of situations, and becoming able to recognize when what one has learned may be appropriately used. ${ }^{11}$

There are several other trends these literatures tell us about the relationship between learning and identity development. From Nasir and others, ${ }^{12}$ we learn that when youth can make connections between their personal identities and what they are doing, they engage better and learn more. They do not, however, always recognize the connections between what they are doing and the things we might want them to learn; they need help in doing that. ${ }^{13}$ Also, fostering such development requires giving learners opportunities for agency ${ }^{14}$ (i.e., for taking their own initiative). Angela Calabrese Barton and Edna Tan ${ }^{15}$

9 Nasir, "Identity, Goals, and Learning," 213-47.

10 Heidi B. Carlone and Angela Johnson, "Understanding the Science Experiences of Successful Women of Color: Science Identity as an Analytic Lens," Journal of Research in Science Teaching 44, no. 8 (2007): 1187-218; Zahra Hazari et al., "Connecting High School Physics Experiences, Outcome Expectations, Physics Identity, and Physics Career Choice: A Gender Study," Journal of Research in Science Teaching 47, no. 8 (2010): 978-1003.

11 Carl Bereiter, "A Dispositional View of Transfer," in Teaching for Transfer: Fostering Generalization in Learning, ed. Anne McKeough et al. (Mahwah, NJ: Lawrence Erlbaum Associates, Inc., 1995), 21-34; Kolodner et al., “Promoting Transfer," 183-232.

12 Na'ilah Suad Nasir, "But When is an Identity: Challenges and Tensions in Operationalizing Identity in the Study of Learning" (paper presented at the annual meeting for the International Society for Cultural and Activity Research, Seville, Spain, August 2006); Nasir and Hand, "From the Court to the Classroom," 143-79; Stanton Wortham, Learning Identity: The Joint Emergence of Social Identification and Academic Learning (New York: Cambridge University Press, 2006).

13 Nasir, "Identity, Goals, and Learning," 213-47.

14 Polman and Miller, "Changing Stories," 879-918.

15 Calabrese Barton and Tan, ““We Be Burnin'!, 187-229. 
suggest letting learners choose roles they will play and allowing them to exert themselves as community experts when appropriate, to encourage development of personal expertise, offering of it to others, and celebrating its use.

On the other hand, when youth are asked to engage with each other according to norms that are not connected to those they identify with, they don't know how to engage, learning is difficult, and they fail to develop enough interest, curiosity, or desire to develop targeted skills and understanding. ${ }^{16}$ Because learners come with different capabilities, interests, and identities, fostering capability and identity therefore requires tapping into the identities of all participating learners. Indeed, one of the key elements in fostering identity and disposition development seems to be balancing the tension between giving learners enough agency that they can choose some of the things they are doing to learn and how to engage in those activities and maintaining enough structure to provide the scaffolding and guidance learners need for success and effective learning.

Joseph Polman ${ }^{17}$ has coined the phrase Zone of Proximal Identity Development (ZPID) to refer to just how close connections to one's identity need to be for new activities to foster learning and further identity development. Similar to L. S. Vygotsky's ${ }^{18}$ Zone of Proximal Development (ZPD), the ZPID is the zone of identity development a learner is ready for: one cannot identify with something one cannot imagine; having experiences that expose more to be imagined is key to developing imagination.

\section{Implications for Designing Learning Environments and Activities}

The recurring claim that participation in a group is key to identity development ${ }^{19}$ suggests the importance of helping people feel they are part of a group as part

16 Bryan A. Brown, “'It Isn't No Slang That Can Be Said about This Stuff': Language, Identity, and Appropriating Science Discourse," Journal of Research in Science Teaching 43, no. 1 (2006): 96-126; Signithia Fordham, "Racelessness as a Factor in Black Students' School Success: Pragmatic Strategy or Pyrrhic Victory?," Harvard Educational Review 58, no. 1 (1988): 54-85.

17 Joseph L. Polman, "The Zone of Proximal Identity Development in Apprenticeship Learning" ("La Zona de Desarrollo Próximo de la Identidad en Entornos de Aprendizaje de Oficios"), Revista de Educación 353 (2010): 129-55; and Polman and Miller, "Changing Stories," 879-918.

18 L. S. Vygotsky, Mind in Society: The Development of Higher Psychological Processes (Cambridge, MA: Harvard University Press, 1978), 79-91.

19 Some colleagues have observed that identity development can also happen through the feeling of opposition to a dominant group. I do not disagree, but I am not familiar with scholarly literature on how to orchestrate such development. I suspect that the practice of making group 
of fostering identity. To feel part of a group, people usually need to feel comfortable interacting with people in the group and enjoy those interactions, find meaning and personal value in the kinds of activities the group engages in, and know that they are being seen by others as being part of the group.

Wenger's stance tells us about the kinds of activities that foster identity development within a community. He suggests that learners need to engage in authentic ways in the activities of the community others want them to identify with-in ways that allow them to imagine themselves playing roles others are playing. Also required, for those who may not have such imagination themselves, is to help learners imagine what they could be in those groups and to help them align themselves with those roles; this means helping them plan toward playing such roles and helping them learn what they need to learn to play those roles.

Therefore, an important issue in developing such learning experiences in the pursuit of Jewish identity will be to identify the practices, beliefs, and other norms of Jewishness that we want learners to take on and decide what authentic activities we should have them do so that they will come to value those norms and learn to do/use them well. Another important issue will be deciding who we want our learners to be interacting with; those who are teaching or facilitating or otherwise playing leadership roles in a group context need to be welcoming, as do already-more-central members. Additionally, it is difficult to engage in authentic ways in the activities of a CoP without enough moreexpert community members available to model ways of learning that learners can imagine and align themselves to. This, in turn, suggests the importance of having the right people modeling and mentoring - those learners can identify with and who are also genuine and authentic practitioners of what we want learners to learn.

But having authentic activities within the context of the community we want learners to identify with is not enough to foster core identity development. From Gee, we learn that fostering core identity requires not simply helping someone learn to do something within a group but also helping learners recognize the value of what they are learning to other aspects of their lives, so that they will be prepared to take some of those values and practices with them and use them outside of the community in which they are learned. The implication is that we should be designing educational systems so that the learners are supported in taking what they are learning in one context into another.

identity explicit would also help those in opposition to that group identity to recognize and articulate their opposition (and thus their identity), but this is, of course, only a conjecture. 
Such support will usually need to be in the context of learning activities, as it is hard to provide support in more ad-hoc situations. One can do this by making sure that the educational environment is set up to help learners value what they are learning and learning to do, recognize the applicability of what they are learning and learning to do, and be given opportunities to practice and experience the effects of taking what they are learning into new contexts.

Finally, Polman's work reminds us that when learners imagine who they are and who they might be, they can only identify as far as their imaginations go. I call this the Zone of Proximal Imagination (ZPI). To help develop learners' imaginations, Polman and Dianne Miller ${ }^{20}$ suggest leveraging the possibilities of the worlds to which learners are already tightly connected (e.g., school, family) and designing "borderland spaces" to facilitate connections to targeted identities. A borderland space is a kind of "figured world," a world created for educational reasons that is similar enough to the real world to be authentic but that helps a learner focus on those aspects of what they are experiencing in ways that will lead to targeted learning.

Taking all of this into account, we can see that designing environments for identity development requires engaging learners in the authentic activities of those with whom we want them to identify in ways that foster development of masterful capabilities and understanding of important content and that help them come to value what they are practicing and learning. We can then help learners imagine beyond what their experiences have been and feel part of a group they come to value (or if they feel apart from that group, to know enough to know deeply what makes them not part of it).

\section{Kitchen Science Investigators: A Case Study in Design for Identity Development}

Armed with the understandings above about identity development and how to foster it and use it to foster learning, two of my students (Tamara Clegg and Christina Gardner McCune) and I set out to design an after-school program to foster scientific identity and disposition development.

Our program was called Kitchen Science Investigators (KSI). ${ }^{21}$ Participants took on cooking and baking goals and learned scientific practices

20 Polman, "Zone of Proximal Identity Development," 129-55.

21 Tamara, L. Clegg, "Kitchen Science Investigators: Promoting Identity Development as Scientific Reasoners and Thinkers" (PhD diss., Georgia Institute of Technology, 2010); 
and science content as they gradually developed expertise in a set of culinary practices. The idea was that cooking and baking would be used to draw them in, and that as they did activities authentic to those of kitchen scientists, they would come to learn and value the practices of scientists that they were enacting (inquiry as well as project practices) and recognize and value the role of the scientific knowledge they were learning in their success.

In early sessions, called Semi-Structured Days, the facilitators posed challenges to the participants in the form of letters to an advice column in a cooking magazine (e.g., "All the recipes for brownies I see seem to result in cakey brownies; I want my brownies to be as gooey as the warm ones I get for dessert in restaurants"). In later sessions, called Choice Days, they chose their own challenges to achieve, often working on them over a several-week period. In the leavening "curriculum," participants learned about using leaveners (e.g., eggs, baking soda, baking powder, yeast) to make breads, cakes, and cookies rise, and all made pizza dough, cakes, and cookies. In the thickening "curriculum," participants learned how to thicken sauces, gravies, and desserts and made a variety of those kinds of dishes. The dishes of their own choosing each required learning some additional science content, ways ingredients work and how to use them, and/or ways of doing things.

Our design of KSI took from Learning by Design elements that we identified as important to learning and identity development among those who participated in it; we adapted those activity sequences and cycles to work in an after-school environment; and we added new components based on the literature cited earlier that specifically focused on identity and disposition development.

From the Learning by Design approach, we took several components:

- Early activities allow participants to gently make their way into the practices we want them to learn and value and to become curious about targeted content, with later activities helping them further

Tamara L. Clegg et al., "Playing with Food: Moving from Interests and Goals into Scientifically Meaningful Experiences," in Learning in the Disciplines: Proceedings of the $9^{\text {th }}$ International Conference of the Learning Societies, ed. Kimberly Gomez et al. (Chicago: International Society of the Learning Sciences, 2010), 1135-42; Clegg and Kolodner, "Bricoleurs and Planners," 239-65; Tamara L. Clegg and Janet L. Kolodner, "Scientizing and Cooking: Helping Middle-School Learners Develop Scientific Dispositions,” Science Education 98, no. 1 (2014): 36-63. 
develop those capabilities, come to value them more, and deepen their understanding of the targeted content.

- Learners engage in sustained inquiry for the purpose of achieving some challenge or mission the curriculum helps them identify with.

- Learners share results, observations, and plans with each other and request advice from their peers.

- Challenges are approached iteratively.

Figure 1 shows how these last three components are integrated and sequenced in Learning by Design units. Investigations are done on a needto-know basis as learners are attempting to achieve a challenge. Presentations are done regularly as learners are both attempting challenges and investigating. Both cycles are iterative cycles, repeated until a challenge is sufficiently achieved.

In addition, for KSI, we sought to build in components that would influence more of the participants toward development of core identities as student scientists or kitchen scientists. We drew these design principles from the literature cited above.

- Learners progress at least part of the time according to their own needs and interests.

- Deeply embedded into activities of the collective is reflection and sharing with participants that highlights the practices being employed, the beliefs behind those practices and their purposes, and the connections between those practices and the practices of the established communities that use those practices. Such sharing and reflection is meant to help participants see themselves as part of an established community and to prepare them to share what they have done, learned, and produced with others outside of the program who are important to them.

- Facilitators grab all the opportunities they can to help participants recognize the authenticity in what they are doing and their successes in engaging in authentic practice, and help participants figure out how they can improve their practice and what they can learn from their experiences.

- Some facilitators are real practitioners of the authentic practices; others are less masterful practitioners but hungry to learn along with participants. 


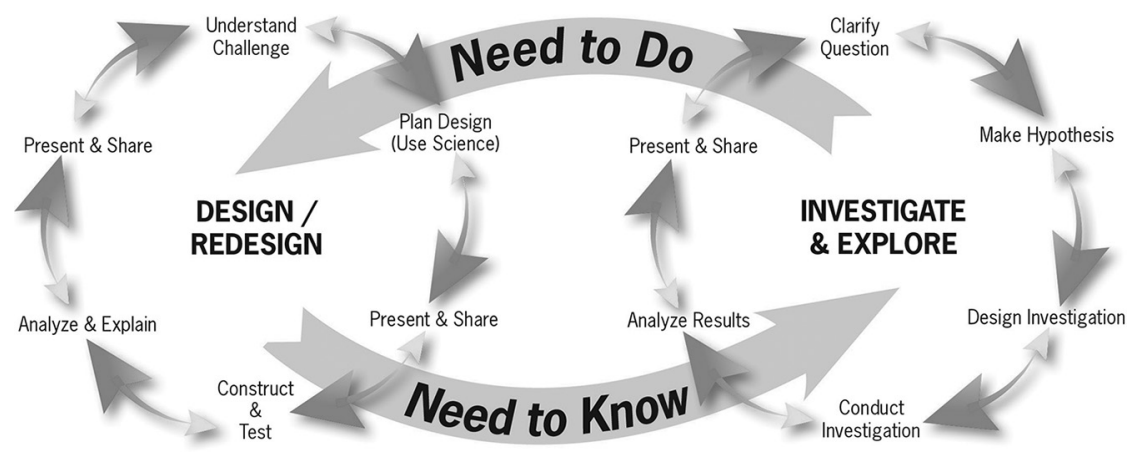

Figure 1: Learning by Design's and PBIS's Cycles. One can think about the left-hand cycle as being one concerned with iteratively addressing goals and challenges and refining one's achievement and solution of those, while the right-hand cycle includes learning activities; originally published in Kolodner, Gray, \& Fasse, 2003.

It all fits together like this. Each session begins with about ten minutes of facilitators helping participants review what they had experienced and having the participants share whatever they wanted with others relating to those experiences. Participants often talked about cooking with a parent or explaining something to a friend or sibling. The facilitator helped them reflect on those experiences and articulate practices, beliefs, and purposes and added commentary connecting what they were reporting to the practices of three types of professionals: investigators, scientists, and kitchen scientists. Then the day's challenge was introduced and discussed (on Structured Days) or the logistics of small-group work was worked out (on Choice Days). On some Structured Days, additional planning was done to organize a Class Experiment and the condition each small group of participants would try so that the experiment would produce sound results. Small groups then worked together for a half hour to an hour, planning, cooking, and doing related recordkeeping and writing, and sometimes including a science activity and its related recordkeeping. Facilitators sometimes worked directly with groups and sometimes kept their eyes on several groups at a time, making themselves available to answer questions, show how to do things, and notice opportunities for pointing out connections between what the participants were doing and what investigators, scientists, or kitchen scientists do. Sometimes facilitators acted as scribes, helping a small group with their recordkeeping and inference making. The whole group got together again after the work period to report back for more sharing and reflection. Sometimes participants would ask about some science content, 
and there would be discussions, presentations, and finding of resources to address learning that content. Sometimes facilitators prepared an activity to help participants experience content (e.g., watching the effects of yeast in different mixtures). On Structured Days, when each small group had carried out some condition of an experiment, time would be spent examining all the data (often that meant measuring, feeling, and tasting the food), making data tables, and drawing inferences together. When each group made something different, time was spent tasting what had been made and giving feedback. And so forth. At the end, the next session was introduced, and discussions were had about the kinds of ingredients facilitators should bring the next time. Sessions lasted an hour and a half to two hours, and participants left with recipes in their hands. The last two sessions were spent preparing for presentations to parents, and parents came for the last hour of the last session to taste their children's creations and hear their stories.

\section{What We Learned}

In the final year of our study, my students (Clegg and Gardner McCune) followed four "focal" participants in depth. Clegg's research goal was to understand how identity and disposition develop and what factors were most important to that development. ${ }^{22}$ Gardner McCune's goal was to understand how learning happens and what it looks like as it is happening when participants engage through a far more informal project-based learning atmosphere than is usual in a classroom. ${ }^{23}$ We collected videos of each small group at work and of the full-group discussions. In addition, Clegg interviewed each of the four focal participants several times during the year and interviewed a parent of each and their science teachers twice.

Each focal participant developed different science-related identitiestwo as kitchen scientists, one as a scientifically minded pastry chef, another as an accurate measurer and understander of units of measurement, and one as a future research scientist (some developed multiple identities). The scientifically minded pastry chef, for example, told us how proud she was that

22 Clegg, "Kitchen Science Investigators"; Clegg et al., "Playing with Food," 1135-42; Clegg and Kolodner, "Bricoleurs and Planners," 239-65; Clegg and Kolodner, "Scientizing and Cooking," 36-63.

23 Christina M. Gardner, "Supporting Cognitive Engagement in a Learning-by-Doing Learning Environment: Case Studies of Participant Engagement and Social Configurations in Kitchen Science Investigators” (PhD diss., Georgia Institute of Technology, 2011). 
she was acquiring skills that would allow her to use science and carry out experiments to perfect her techniques and recipes when she joined the profession. She had already identified as a future pastry chef when she joined our program; now she was differentiating herself from the rest of the pack and beginning to understand the special identity she would have within the profession. The accurate measurer showed her identity in science class. The class was engaged in running an experiment that required careful measurement. This young woman took it on herself to help the rest of her group understand the importance of making sure the units of measurement were being followed and showing them how to carefully measure out the correct amounts. When her teacher noticed, she had this young woman help the whole class understand these practices and ideas. This participant reported to us her pride that she was able to teach the others and her feelings of competence and confidence. She felt she was prepared now to participate well in science labs in the future and even to think about such activities as something she could participate in in later life.

Overall, Clegg was able to develop case studies of the identity development of each of the focal participants based on what each shared with her about what she had learned and who she was becoming; what each shared with parents, friends, and/or classmates; and through reports from the participants, their parents, and their teacher about the participant's behaviors and talk, Clegg was able to track how the practices and ways of doing they were learning in KSI were becoming integrated into their everyday activities and core identities and some of what was responsible for that development. Some of what we had built into the program was important to that development (e.g., iteration - the opportunity to fail, getting help with explaining what happened, and having the opportunity to try again; others valuing what participants taught them and giving participants pats on the back), and some things we did not design for were made possible by experiences in KSI (e.g., sibling rivalry in which one of the participants got to teach her older brother something about science, interactions in informal ways with their teachers, getting to know and identifying with the graduate students running the program). These studies thus demonstrated a lot about what makes a difference in fostering identity and disposition development. $^{24}$

24 Clegg, "Kitchen Science Investigators"; Clegg and Kolodner, "Scientizing and Cooking," 36-63. 
Our analysis added confirmatory evidence to some of the theory we used to design KSI and helped us learn additional lessons about learning and identity development.

- Learners did indeed sustain their engagement over long periods of time (some as many as twenty weeks, and they wanted to continue) when they were learning science content and practices in the context of doing something interesting, important, and familiar to them.

- $\quad$ Every participant learned content and skills, but, as expected, they did not all learn the same things; nor did they learn at the same pace. Each learned more about what she was interested in than about other things; the will to succeed at goals they were undertaking led each of the participants to focus on learning those things important to achieving her goals. The participant we identified as a measurer, for example, was chagrinned when her group-mates put 1/4 cup of baking soda into a cooking recipe rather than $1 / 4$ teaspoon. She paid special attention to units from then on and made sure she paid attention to units in every recipe, learned how to measure different ingredients, and used different kinds of measuring methods; she later made herself a go-to person for measuring advice in her science classroom. She experienced her success in doing that and that others appreciated her skill. The participant who wanted to be a pastry chef someday was particularly interested in the roles of different thickeners and how they work. Another paid special attention to the scientific practices and used what she was learning to do to make sense of what scientists in the world do; she had always been interested in science but had not had a chance to make sense of what that meant before.

- Because what participants were doing as they designed and ran cooking experiments and applied what they were learning to recipe perfection was authentic to the practices of investigators, scientists, and kitchen scientists in the real world, and because facilitators helped participants recognize that, participants were able to take what they had learned about science practices to other venues in their lives. The participant who learned about measurement took what she learned into science class and helped her classmates learn. The participant who had previously been interested in what scientists do paid new attention in science class and argued with her older brother about what is real science. Some participants began 
looking at ingredients while out food shopping with their moms. All of the participants remade recipes at home, tried out new similar techniques at home, and taught their family and/or friends what they were learning.

- $\quad$ All got pats on the back from their parents, teachers, and friends after sharing what they were learning and/or the dishes they had made; they reported that it made them feel confident, proud, and like scientists and investigators.

- When the room setup allowed and encouraged informal interactions across work groups, there was much informal sharing going on as participants were preparing their foods; they got ideas and became curious when they saw what others were doing. ${ }^{25}$

- It was the first time for many participants that they felt that their ways of thinking were valued, and this made them ready to recognize how they could enhance their capabilities in more scientific ways.

- Participants reported that their interactions with facilitators who are scientists gave them a whole new appreciation of what a scientist is and could be. It is important to mention, here, that the participants were girls of color, and most of our facilitators were also. It was the first time some participants thought about themselves as people who could be scientists, even though most expressed at least some interest in science from the start.

- $\quad$ Since cooking and eating are things that people do in multiple venues and with multiple groups, what the participants were doing in KSI had connections to many different facets of the their lives; this made it easy to have opportunities to share what they were doing and learning with others.

- Two connections between formal and informal education were quite important to the identity development of focal participants. (a) Teachers got to see participants playing roles as student scientists, and participants got to interact with their teachers in a more informal setting than the classroom. Teachers gained an appreciation of what the participants in KSI could do and called on them more and expected more of them in class; participants had a new appreciation for their teachers as people and were more willing to participate. The new dynamic may have been life-changing for

25 Gardner, "Supporting Cognitive Engagement." 
some of these girls. (b) Participants made friends with students they would not have otherwise become friends with. It was easy to continue these friendships in science class, since they knew things and had experiences that others had not had. In all cases, this led to more attentive and engaged work in science class (though all participants continued to complain that science class was not enough like the science they were doing in KSI).

\section{Jewish Identity and Disposition}

So what does any of this have to do with Jewish identity and Jewish dispositions and their development? It has been clear for a long time that only some of our youth benefit from our Hebrew schools. Many more benefit from certain kinds of Jewish summer camp experiences, but fewer of our youth participate in those. Those of us who enjoy being Jewish find it a shame that so many of the Jewish population don't know enough to be able to enjoy being Jewish in the same ways we do. Those of us who hope for a robust Jewish future want more of our population to both identify Jewishly and practice Jewishly (whether as Reform, Conservative, Orthodox, cultural, or post-denominational Jews). Those of us who are Zionist want our children to celebrate the achievement that the State of Israel represents, to identify with Israel as our homeland, and to contribute to the fulfillment of our aspirations for the State. Whatever the goals, the kinds of engagement with Judaism we want our Jewish schools to engender requires that our youth identify themselves as some kind of Jewish, gain understanding of what that means and how to do that kind of Jewish, become knowledgeable about why Jewish people do as they do and about the history of those practices, and take it on themselves to participate in life in Jewish ways. One's sense of oneself as a Jew should coalesce with knowledge and behavior related to this.

Though development of science identity and Jewish identity seem quite different from each other on the surface, I argue that they share the same challenges and that guidelines developed for fostering each can inform fostering of the other. As a beginning to supporting this argument, I point out that the particular foundational approaches to identity development that I focus on in my analysis (those of Erikson, Wenger, Gee) address development of core identity in general rather than on development of specific identities. They all suggest that core identity develops as a process of developing situational identity through engaging with groups and integrating aspects of one's 
different situational identities into one's core identity through trying them on in other contexts of one's life. Those who build on those theories (Nasir, Polman, Clegg) focus on interactions between those processes and processes involved in gaining understanding, competence, and imagination, adding to those foundations new findings about the cognitive, social, and affective processes that influence situational and core identity development. Though they study identity development in specific contexts, their research focuses on drawing out lessons about identity development that apply more generally across development of different types of identities. When my students and I draw lessons from our work on developing science and engineering identity, we are focusing similarly, analyzing our data from the perspective of these foundational theories so as to be able to add to the understanding of how core identity develops and to make suggestions about fostering core identity development that are applicable beyond the particular contexts in which we do our research. Whatever the core identity development we are seeking to foster, we need to be mindful of these and complexities of influencing that development:

- Core identity development begins in situational settings in the contexts of activities that participants find meaningful and in the contexts of communities that learners enjoy engaging with, that give them opportunities to develop expertise, be recognized for their expertise, and become more central to the operations of the community, and that reward them for their growing capabilities.

- Core identity development takes significant time and happens as learners try out the attitudes and practices of their developing situational identities in new situations and in the contexts of other communities they engage in.

- A requirement for learners to take the initiative to try out those attitudes and practices in new situations is that they know something about when those attitudes and practices apply and feel enough competence and confidence that they think they can be successful and that their attempts will be appreciated in those new situations. Gaining understanding and developing disposition require development of identity and also the converse: as identity is developing, we need to help our youngsters learn practices, gain understanding, and grab opportunities to apply what they are learning.

- Core identity development is strengthened with each attempt to use situationally developed beliefs, attitudes, and practices in a new 
context or with a new community, provided learners have a chance to debug their failures and be valued for their attempts.

Identity development, thus, is not something any one educator or educational institution can have complete control over; different participants in the same well-designed environment for fostering learning and identity will learn different things from those experiences and develop identity and disposition differently than others because of what they are already familiar with as well as because of the other experiences they have. And given the variability in the activities and communities our learners participate in, we have little control over the opportunities they will have to try out what they are learning and therefore little control over whether they will feel confident or competent in those situations or have the capabilities to be successful in those situations.

My conclusion, then, is that our best chances of fostering positive Jewish identity development will come from a combination of (a) helping our youngsters have experiences with the qualities discussed above over a variety of environments and as part of a variety of communities and community members; (b) helping them reflect on how what they are learning and becoming might be called on in the variety of other situations they encounter in their lives; (c) helping them reflect on their expression (or lack thereof) of values and ways of doing things between the Jewish environments they engage in and other environments; and (d) helping them anticipate and negotiate the tensions and challenges involved in the expression of their Jewish values and ways of doing things in non-Jewish environments and situations. To make that happen, we need to clarify the values and practices we and the organizations we belong to subscribe to and what we want our youngsters to know and to know how to do, we need to clearly articulate the ways of being Jewish that we want our youngsters to consider and make their own, and we need to design experiences for them that will help them both learn what we want them to learn and internalize the values in those beliefs, attitudes, and practices. It is not simple, but it is not impossible either. It will require, I believe, development of educational and social opportunities across organizations (e.g., camps and schools) and across usually siloed departments or divisions within those organizations (e.g., youth group and education functions of synagogues). It will benefit, as well, from involving experts in the conceptual foundations of identity development (i.e., the literature I cite here) and 
in designing for identity development as members of educational planning groups along with Jewish education professionals.

Whatever the specific Jewish outcomes we are aiming for in Jewish education, we want learners to become competent and capable within those domains, to have confidence in what they can do and what they know, to be aware of the Jewishness of what they are doing, to take pride and enjoy what they are doing, and to find it meaningful. The literature above and what was learned through the KSI experience suggest building blocks for achieving such goals. 


\section{Bibliography}

Barton, Angela Calabrese, and Edna Tan. “We Be Burnin'! Agency, Identity, and Science Learning." Journal of the Learning Sciences 19, no. 2 (2010): 187-229.

Bereiter, Carl. "A Dispositional View of Transfer." In Teaching for Transfer: Fostering Generalization in Learning. Edited by Anne McKeough, Judy Lupart, and Anthony Marini, 21-34. Mahwah, NJ: Lawrence Erlbaum Associates, Inc., 1995.

Blumenfeld, Phyllis C., Elliot Soloway, Ronald W. Marx, Joseph S. Krajcik, Mark Guzdial, and Annemarie Palinscar. "Motivating Project-Based Learning: Sustaining the Doing, Supporting the Learning." Educational Psychologist 26, no. 3-4 (1991): 369-98.

Brown, Bryan A. "It Isn't No Slang That Can Be Said about This Stuff': Language, Identity, and Appropriating Science Discourse." Journal of Research in Science Teaching 43, no. 1 (2006): 96-126.

Carlone, Heidi B., and Angela Johnson. "Understanding the Science Experiences of Successful Women of Color: Science Identity as an Analytic Lens." Journal of Research in Science Teaching 44, no. 8 (2007): 1187-218.

Clegg, Tamara, L. "Kitchen Science Investigators: Promoting Identity Development as Scientific Reasoners and Thinkers." PhD diss., Georgia Institute of Technology, 2010.

Clegg, Tamara L., and Janet L. Kolodner. "Bricoleurs and Planners Engaging in Scientific Reasoning: A Tale of Two Groups in One Learning Community." Research and Practice in Technology Enhanced Learning 2, no. 3 (2007): 239-65.

. "Scientizing and Cooking: Helping Middle-School Learners Develop Scientific Dispositions.” Science Education 98, no. 1 (2014): 36-63.

Clegg, Tamara L., Christina Gardner, Janet L. Kolodner. "Playing with Food: Moving from Interests and Goals into Scientifically Meaningful Experiences." In Learning in the Disciplines: Proceedings of the $9^{\text {th }}$ International Conference of the Learning Societies. Edited by Kimberly Gomez, Leilah Lyons, and Joshua Radinsk, 1135-42. Chicago: International Society of the Learning Sciences, 2010.

Erikson, Erik H. Dimensions of a New Identity. New York: W. W. Norton \& Company, 1979.

Fordham, Signithia. "Racelessness as a Factor in Black Students' School Success: Pragmatic Strategy or Pyrrhic Victory?” Harvard Educational Review 58, no. 1 (1988): 54-85.

Gardner, Christina M. "Supporting Cognitive Engagement in a Learning-by-Doing Learning Environment: Case Studies of Participant Engagement and Social Configurations in Kitchen Science Investigators." PhD diss., Georgia Institute of Technology, 2011. 
Gee, James Paul. "Identity as an Analytic Lens for Research in Education." Review of Research in Education 25 (2000-2001): 99-125.

Gresalfi, Melissa Sommerfeld. "Taking Up Opportunities to Learn: Constructing Dispositions in Mathematics Classrooms." Journal of the Learning Sciences 18, no. 3 (2009): 327-69.

Gresalfi, Melissa Sommerfeld, and Adam Ingram-Goble. "Designing for Dispositions." In Cre8ing a Learning World: Proceedings of the $8^{\text {th }}$ International Conference for the Learning Sciences. Edited by Paul A. Kirschner, Geroen J. G. van Merrienboer, and Ton de Jong, 576-83. Utrecht, the Netherlands: International Society of the Learning Sciences, 2008.

Gresalfi, Melissa Sommerfeld, and Paul Cobb. "Cultivating Students' Discipline-Specific Dispositions as a Critical Goal for Pedagogy and Equity." Pedagogies: An International Journal 1, no. 1 (2006): 49-57.

Hazari, Zahra, Gerhard Sonnert, Philip M. Sadler, and Marie-Claire Shanahan. "Connecting High School Physics Experiences, Outcome Expectations, Physics Identity, and Physics Career Choice: A Gender Study." Journal of Research in Science Teaching 47, no. 8 (2010): 978-1003.

Holland, Dorothy, William Lachicotte Jr., Debra Skinner, and Carole Cain. Agency and Identity in Cultural Worlds. Cambridge, MA: Harvard University Press, 1998.

Kolodner, Janet L. "The Roles of Scripts in Promoting Collaborative Discourse in Learning by Design." In Scripting Computer-Supported Collaborative Learning: Cognitive, Computational and Educational Perspectives. Edited by Frank Fisher, Ingo Kollar, Heinz Mandl, and Jorg M. Haake, 237-62. New York: Springer Science+Business Media, 2007.

Kolodner, Janet L. et al. Project-Based Inquiry Science (PBIS). 13 vol. Mt. Kisco, NY: It's About Time, 2013.

Kolodner, Janet L., Jacquelyn T. Gray, and Barbara Burks Fasse. "Promoting Transfer through Case-Based Reasoning: Rituals and Practices in Learning by Design Classrooms.” Cognitive Science Quarterly 3, no. 2 (2003): 183-232.

Kolodner, Janet L., Mary L. Starr, Daniel Edelson, Barbara Hug, David Kanter, Joseph Krajcik, Juliana A. Lancaster et al. "Implementing What We Know About Learning in a MiddleSchool Curriculum for Widespread Dissemination: The Project-Based Inquiry Science (PBIS) Story." Proceedings of the 8th International Conference for the Learning Sciences (ICLS). Edited by Paul A. Kirschner, Geroen J. G. van Merrienboer, and Ton de Jong, 274-281. Utrecht, the Netherlands: International Society of the Learning Sciences.

Kolodner, Janet L., Paul J. Camp, David Crismond, Barbara Fasse, Jackie Gray, Jennifer Holbrook, Sadhana Puntambekar, and Mike Ryan. "Problem-Based Learning Meets CaseBased Reasoning in the Middle-School Science Classroom: Putting Learning by Design into Practice." Journal of the Learning Sciences 12, no. 4 (2003): 495-547.

Lave, Jean, and Etienne Wenger. Situated Learning: Legitimate Peripheral Participation. Cambridge, UK: Cambridge University Press, 1991.

Nasir, Na'ilah Suad. "But When is an Identity: Challenges and Tensions in Operationalizing Identity in the Study of Learning." Paper presented at the meeting of the International Society for Cultural and Activity Research, Seville, Spain, August 2006. 
52 Janet L. Kolodner

"Identity, Goals, and Learning: Mathematics in Cultural Practice." Mathematical Thinking and Learning 4, no. 2-3 (2002): 213-47.

Nasir, Na'ilah Suad, and Victoria Hand. "From the Court to the Classroom: Opportunities for Engagement, Learning, and Identity in Basketball and Classroom Mathematics." Journal of the Learning Sciences 17, no. 2 (2008): 143-79.

Polman, Joseph L. "The Zone of Proximal Identity Development in Apprenticeship Learning" ("La zona de desarrollo próximo de la identidad en entornos de aprendizaje de oficios"). Revista de Educación 353 (2010): 129-55.

Polman, Joseph L., and Diane Miller. "Changing Stories: Trajectories of Identification Among African American Youth in a Science Outreach Apprenticeship." American Education Research Journal 47, no. 4 (2010): 879-918.

Schön, Donald A. The Reflective Practitioner: How Professionals Think in Action. New York: Basic Books, 1983.

Vygotsky, L. S. Mind in Society: The Development of Higher Psychological Processes. Cambridge, MA: Harvard University Press, 1978.

Wenger, Etienne. Communities of Practice: Learning, Meaning, and Identity. Cambridge, UK: Cambridge University Press, 1998.

Wortham, Stanton. Learning Identity: The Joint Emergence of Social Identification and Academic Learning. New York: Cambridge University Press, 2006. 